\title{
CLÁUSULAS DE MODIFICACIÓN UNILATERAL DE LOS CONTRATOS: ENTRE NECESIDAD Y ABUSIVIDAD
}

\author{
José Manuel Gual Acosta9
}

Buenos días, doy un cordial saludo a las directivas del Politécnico quienes me han hecho el honor de invitarme a este Seminario. Extiendo este saludo a las colegas y los colegas que, en su momento, fueron mis estudiantes en pregrado y posgrado; así como a todos los demás asistentes que nos brindan su atenta y agradable participación.

El tema que me han asignado corresponde al de las cláusulas de modificación unilateral, lo cual siempre deja dudas frente a su tipología y control; en especial, si se quiere saber hasta dónde este tipo de cláusulas son necesarias o realmente terminan siendo abusivas.

Se parte de la controversia que podría darse cuando en el contenido contractual predispuesto por unas partes dentro de un negocio, al momento de la celebración del mismo, una de las partes adhiere a un contenido en el que solo a una de ellas se le ha otorgado la facultad contractual unilateral de modificar los contenidos contractuales; a las obligaciones a que se ha sometido en el contrato inicialmente pactado, lo cual al parecer es válido bajo el imperio del principio de la autonomía privada y las libertades contractuales que del mismo derivan.

En teoría, resulta claro que el contrato y sus pactos, son ley para las partes. Por demás y bajo los parámetros de la seguridad negocial, entonces, este nos obliga a lo pactado. Ambos principios contractuales rigen para los contratos bilaterales y, en consideración a ello, las obligaciones que de ellos surjan someterán a las partes.

Piense que usted en medio del desarrollo del contrato o durante su ejecución, se encuentra frente al hecho que la otra parte en un contrato de distribución o de construcción, decide cambiar o

9 Abogado de la Universidad Externado de Colombia. Especialista en derecho de negocios de la misma universidad. Doctor en derecho civil en el área de la responsabilidad de la Escuela Superior de Pisa. Asesor y consultor de entidades públicas y empresas privadas. Árbitro de la Cámara de Comercio de Bogotá. Exmagistrado auxiliar de la Corte Suprema de Justicia de la sala civil. Docente de la Universidad Libre de Bogotá. Actualmente es profesor de posgrado en la Institución Universitaria Politécnico Grancolombiano. 
modificar de manera unilateral algunas condiciones contractuales de las inicialmente pactadas y que seguramente lo llevaron a contratar: como las calidades, apariencia o envases de los productos.

Así las cosas, en un contrato de construcción de un edificio en un conjunto residencial, el constructor decide cambiar las profundidades de la piscina, o cambiar la dotación del gimnasio, o simplemente suprimir un jardín para colocar un parque o eliminar un jacuzzi comunal. Lo mismo en un contrato de distribución de bebidas carbonatadas o gaseosas, en el que se decide cambiar el material del envase o algún tipo de empaque en otro tipo de productos. Piense que para el distribuidor se hace necesario cambiar la botella envasada en plástico por una en vidrio retornable; no obstante, el sobrecosto que eso trae a él mismo y decide hacerlo; con base en la aplicación de una cláusula de modificación unilateral, que usted pactó en su favor para que lo hiciera. Bien, de manera automática si acontecen algunos eventos ajenos a esa parte fuerte; o si en cambio, se necesita su autorización, dejándole la opción sea de retirarse del negocio, pagando los saldos que se adeuden y multas por terminación del contrato... o en cambio, la de seguir, pero con ajuste de precio, el cual en este caso sería un aumento unilateral.

En otros eventos, en cambio, como ocurre con los contratos bancarios, la aplicación de la modificación unilateral, opera con la simple comunicación que la entidad financiera da al consumidor financiero informándole que ha modificado la tasa de crédito (lo que ocurrió en Chile con el caso CENCOSUD del grupo propietario de Jumbo). Eso sí, dejando a la otra parte la opción de seguir con el contrato o retirarse, pero poniéndose al día con todas las cuotas del mutuo y sin que pueda alegar daño alguno, bajo el argumento que así se había pactado de manera previa. Situación similar podría darse en materia de contratos de suscripción de servicios de comunicaciones de telefonía móvil o de TV por suscripción, en los que la compañía prestadora decide cambiar la tarifa de manera unilateral o no enviar más las cuentas de cobro por medio de papel físico sino por correo electrónico.

Piense en otro caso muy sensible y que suele suceder cuando usted compra un apartamento y, de pronto, empieza a subir el precio de los insumos; situación que termina por hacer elevar el costo de la obra para el constructor. Usted diría un típico caso de imprevisión, es decir, un precio excesivo que termina por dejar al constructor con menos ganancias. Entonces, 
el constructor como vendedor experto profesional y previendo que eso puede pasar tal y como le suele suceder por su experiencia, de manera previa, ha pactado en forma de cláusula de imprevisión ante ciertos eventos externos a él dentro del texto de la promesa de compra: que de darse esa situación en algún momento de la ejecución del contrato, él podrá cambiar el precio inicialmente estipulado al momento en que se firmó la promesa, lo que incrementará el precio de la compraventa, previo aviso de tres meses, antes de la firma de las escrituras de la venta misma. Entonces, si pensamos en un apartamento cuyo valor inicial era de 400 millones de pesos al momento de celebrarse la promesa, lo que normalmente sucede unos 24 meses antes de la venta y usted debido a esa cláusula de modificación unilateral termina por firmar un contrato de compraventa con un nuevo valor incrementado en 50 millones. Lo que, con base en lo pactado en la promesa, le obliga a cumplir con el nuevo precio de la compra, surge la inquietud ¿una cláusula de modificación unilateral del precio inicialmente pactado sería válida? Como consecuencia de las fluctuaciones de los insumos, por la variación del dólar en donde esta operaría, incluso, como una cláusula de reajuste.

Uno podría pensar que tal cláusula es equilibrada y justa para las partes, en la medida que cuando uno compra un inmueble sobre planos, la idea es que con esa inversión se suele ganar el $20 \%$ del valor pagado al momento de la entrega del inmueble; por aquello que se llama valorización. Pero gracias a esa cláusula de modificación resulta que, esta vez, el constructor será el favorecido con la valorización como parte de sus ganancias; contrarrestando las posibles pérdidas por el sobrecosto de insumos. Surge una vez más la pregunta: ¿Este tipo de pacto es válido?

Ahora supongamos el evento en que no se consagre tal cláusula modificativa del precio de manera unilateral por parte del constructor dentro del texto del contrato, sino que simplemente, las condiciones contractuales varían porque el constructor así lo determina de manera unilateral y decide eliminar cierta zona común o cambiar su tamaño porque ello así le pareció. $O$ cuando debido a un hecho ajeno a su voluntad, como una nueva ley, no usa tejas de Eternit con el fin de prevenir contagios de la asbestosis que se transmite por las fibras de amianto o asbesto usadas en la elaboración de las tejas de fibrocemento producidas por la famosa empresa, tejas que son empleadas en techos de casas, hospitales y escuelas (material que, no obstante estar prohibido en Europa, aún se emplea en Colombia en tanques, tuberías, tejas onduladas y se fabrica en la India). Resulta ahora que como en el contrato pactado se había pensado usar esta clase de teja, ahora, para que el contrato siga cumpliendo su objeto acorde a la nueva normativa, el constructor deberá cambiar esas tejas 
por unas de plástico, que proporcionan prestaciones similares; pero me incrementan los costos de obra, no obstante, proporcionando al usuario un menor riesgo a su salud. Esto hace que se incremente el precio de las soluciones de vivienda.

Resulta claro que nadie está obligado a cumplir con algo diferente a lo pactado, como tampoco a recibir algo diferente así sea más costoso. Pero con la nueva normativa, lo razonable parece cambiar la especificación del tipo de teja, para que el contrato se mantenga a fin de que se pueda cumplir. Además, para que sea acorde con las políticas de salubridad pública, el problema será determinar quién asumirá esos nuevos sobrecostos. Entonces, ¿se podrá modificar el precio de manera unilateral con cargo al otro contratante?, ¿se necesitará, de manera previa, autorización o pacto al respecto en el contrato? Con base en la imprevisión, ¿se podría dar una modificación unilateral o buscar el acuerdo previo que, en caso de no darse, daría lugar a una terminación del contrato, así sea por vía judicial?

Surgen varios interrogantes, pues además de determinar si ese tipo de cláusula de modificación unilateral sería válido: ¿Deberá el comprador adaptarse a las nuevas condiciones de precio o, en cambio, demandar la resolución del contrato por cambio unilateral de uno de los elementos esenciales del contrato como el precio?, ¿valdrían una de esas cláusulas cuando opera la modificación como consecuencia de un evento ajeno a la voluntad de las partes? Si la cláusula de modificación no existiera, ¿sería posible un ajuste de precio de manera unilateral?, ¿incluso cambiar la calidad, cantidad o tipo de materiales, a fin de compensar costos con las nuevas adaptaciones?, ¿o simplemente el contrato tendría que dejar de ejecutarse o terminarse como consecuencia del advenimiento de una situación imprevista por las partes?

Son estas situaciones las que nos genera interrogantes, pues ¿hasta dónde las partes podrían pactar este tipo de cláusulas, para mantener vivo el contrato? Porque si la cláusula no existiera, posiblemente habría un incumplimiento; cuando con ella la idea es evitarlo y más bien cumplir con unas condiciones razonables que permitan que el contrato se mantenga.

Resulta claro que pactar de manera previa en un contrato cláusulas de modificación unilateral, permitirán tan solo a una de las partes (la cual es la predisponente, por lo general) cambiar 
en forma unilateral un elemento del contrato; lo cual sería útil al permitir a una de las partes (generalmente, la experta en el negocio), adaptarlo frente a los cambios que se pudieran dar durante su desarrollo.

De manera que una ausencia contractual de la cláusula de modificación unilateral, en principio, no permitiría cambio alguno sobre el contendio negocial, en aplicación del principio pacta sunt servanda. Sin embargo, ella suele ser considerada como una cláusula potencialmente abusiva dentro de los listados grises, si se observa la Directiva UE 13/93 y UE 83/11 en Europa. Y en Colombia, con claridad son abusivas al estar dentro del listado negro del artículo 43 de la ley 1480/11 o Estatuto del Consumidor. Lo cual, a mi entender, es un control excesivo para una cláusula que, a veces, puede resultar útil para mantener la vigencia del contrato; ante el hecho de presentarse ciertos eventos imprevistos y ajenos a la voluntad de alguna de las partes.

Sin embargo, en materia de contratos entre empresarios (B2b), como sería el contrato de distribución, no parece que resulte tan evidente un control sobre la abusividad. Lo cierto es que ella es posible por un mecanismo de control, al menos con base en los principios del Derecho como son: la buena fe, la transparencia, el cumplimiento de deberes de información y el equilibrio normativo entre las partes. Esta posición no resulta ajena en los ordenamientos portugués, alemán, italiano y, más reciente, en el francés.

Supongan que ustedes producen bebidas gaseosas (hoy día con una botella bastante contaminante, que tarda en desaparecer 400 años) ... pero con la pereza de cargar botilito o termo, como antes, los llevaba a la escuela o adonde saliera de paseo. Hubo una época desde los 90, en que no se usaban... ahora se vuelve a ellos por la consciencia ambiental; pues si lleva un refresco (sea gaseosa, jugo o agua) en una botella PET, por cada litro que consume son 8 botellitas y piense cuántas serían al año... cuánto consume durante los ochenta años de vida que le quedan si es varón y si es mujer un poco más. El planeta y sus hijos lo agradecerán y seguramente eso llevaría a las embotelladoras a no producirlas, pero depende de su actitud como un consumidor informado y responsable.

Entonces, si se emitiera una ley ambiental, con un gobierno que hiciera algo realmente en favor del ambiente, en la cual las nuevas embotelladoras debieran hacer como antes, es decir, botellas solo de vidrio cuya contaminación es " 0 " porque al lavarlas, son retornables el consumidor las devuelve. Pues recuerdo que uno compraba la gaseosa en una tienda y luego la devolvía, porque era botella de 
vidrio que no contaminaba porque era retornable. La de PET no desaparece nunca, esa botella deberían eliminarla definitivamente; pero bueno, los jóvenes tienen esa consciencia más que nosotros claramente están en eso. Las grandes embotelladoras que argumentan que a la gente le gusta transportar su botella personal de PET y por eso las consumen (no obstante, ser plástico de un solo uso). Entonces, si con esas leyes nuevas ideales, yo como compañía tendría que adaptarme a las nuevas leyes y por ende mi tienda distribuidora; de manera que tendré que decirle: "Mire señor distribuidor, la ley me prohíbe sacar botellas de plástico y esto me incrementa un costo".

Entonces, cuando la gran empresa tiene un sobrecosto lo externaliza en los consumidores por medio del distribuidor, mediante un alza de precios, pues la idea es no perder ganancias. Pero, al adaptarme entonces a ese nuevo costo, ¿quién va a perder la ganancia? La gran empresa seguramente que no, de manera que será el distribuidor llamado tienda o el consumidor; pues yo a mi distribuidor le he dado publicidad en su local, he hecho en él una inversión, ya que le he puesto neveras o mostradores para que ponga las bebidas.

De manera que el empresario fuerte, va a trasladar el costo de esa ley nueva de carácter ambiental, al consumidor. Pero, como se trata generalmente de franquicias, tampoco me puedo permitir que el precio aumente, pues corro el riesgo de volverme poco competitiva ante la competencia. Por ejemplo, supongamos que soy McDonald's y entonces tengo un precio estándar, pero no puedo dejar que el precio suba, sino que el sobrecosto bien se podría asumir con un aumento en los valores de la franquicia y la mensualidad que por ella pagan, pues, las ventas no deben caer e igual el titular de la franquicia ganará; pero el explotador de la misma también, así gane un poco menos.

Pensemos, ¿cuánto costaría adaptar el empaque de un producto que se vende en bandejas o cajas de icopor, el cual tampoco desaparece nunca, y pasarlo a empaques de cartón reciclado? Es más costoso. Entonces, adaptar un contrato a estos cambios ambientales normativos de carácter imperativo, implicaría que la gran empresa pueda modificarlo unilateralmente; de lo contrario, la única opción es su terminación, porque no sería rentable económicamente. Nadie quiere dejar de ganar, es un tema de comercio y los que son comerciantes saben que uno compra a un precio y lo vende al 
doble, si no el comercio no crece... y es claro, por la alta tributación, el precio final tiene que ser muy cercano el doble.

Sin embargo, en Colombia está la cláusula de modificación unilateral, está proscrita con relación a los contratos de consumo, pues el Estatuto del Consumidor (ley 1480/11) prohibe su inclusión en esos contratos (num. 7, art. 43).

Lo mismo sucede cuando se da un plazo para la entrega de un apartamento sobre planos y en vísperas de la entrega, la constructora le informa al comprador, que la fecha de entrega se aplaza a tres meses. No obstante, el futuro propietario ha pagado el bien de contado o esté viviendo en arriendo o ha tomado un préstamo bancario para poder cumplir; de manera que la constructora le cumplirá sin retardo en la entrega, gracias al nuevo pacto de plazo sin derecho a responsabilidad alguna que resulta de lo pactado, gracias a una cláusula de modificación unilateral y que le permitió adaptar el contrato a unos nuevos plazos, a fin de evitar el retardo, el cual se amplió en tres meses más.

El problema es que para el consumidor ese retardo y ahora con nuevo plazo de entrega le ocasiona un sobrecosto, que resulta reflejado en tres meses más de pago del canon de arriendo. Por demás, la constructora amplía el plazo, sin derecho a intereses por mora o remunetarios sobre la cifra que se ha dado. Esto ya inicia a parecer abusivo o al menos gravoso para el comprador, que sigue pagando un dinero en cánones de arriendos que de haber cumplido en tiempo y sin modificación unilateral de los plazos, se indemnizarían por el retado en la entrega. No obstante, la constructora se demora más de lo estipulado en la promesa sobre la entrega material del bien $y$, no solo hace el cambio de fecha de entrega, sino que además lo hace negando cualquier posibilidad de reconocimiento de daños por retardo o mora; lo que en este caso constituye otra de las cláusulas que también suelen ser abusiva en Derecho de Consumo. Me refiero a la cláusula de exoneración o limitación de responsabilidad.

La situación hasta ahora planteada ilustra, de alguna manera, una potencial abusividad. Pensemos, en cambio, que debido a un alto índice de pluviosidad y el aumento desmedido del cemento, el constructor para poder cumplir, simplemente cambia la fecha de entrega en tres meses más; como se observa es un simple evento en que unos ajustes se acuerdan por una situación sobreviniente que tornó muy onerosa la prestación, no obstante no se podría catalogar de fuerza mayor. 
Así las cosas, para tratar de volver a equilibrar el contrato y lograr su adaptación para el cumplimiento, su uso parecería más normal en contratos de distribución o en contratos de larga duración, como ya se ha mencionado, en el caso de la construcción de inmuebles. Lo cierto es que ello sí aplica en los contratos de obra pública sin que sea abusivo, en la medida que la misma Ley 80/93 o Estatuto de Contratación Estatal lo permite, en favor del Estado en ejercicio de las facultades exorbitantes; y es ahí donde más se suelen utilizar y aparecen como una figura necesaria para adecuar los contratos que se están cumpliendo con ánimo de apoyar y colaborar con el Estado.

Supongamos ahora que usted es un importador y hace un contrato de compraventa con un distribuidor. Sin embargo, la mercancía no le llega, por ejemplo, porque el barco en que se transportaban los insumos se accidentó en altamar y lo están arreglando; y mientras se hizo el trasbordo, la mercancía se demoró una semana más sobre el plazo.

Es de anotar que esta cláusula no aparece en el listado de cláusulas abusivas del Estatuto del Consumidor, pero ellas podrían controlarse a la luz del artículo 42 del mismo Estatuto, bajo el criterio general; sin embargo, están consagradas dentro del listado de lista gris de las Directivas europeas UE 13/93 y $83 / 11$.

Resulta por lo antes expuesto, que el uso de las cláusulas de modificación unilateral, si bien resultan útiles, solo se justificarán y serán válidas siempre que busquen mantener el equilibrio de las obligaciones y deberes de las partes del contrato; con la finalidad de satisfacer los intereses de las partes mediante el cumplimiento y así evitar la resolución o terminación del contrato mismo, lo cual las haría equilibradas y acordes a la buena fe.

También es cierto que como los contratos obligan a lo que está en ellos estipulado como un principio de la contratación, no se ve con claridad como podría una de las partes modificar unilateralmente el contrato si esa posibilidad no se pactó. Sin embargo, se puede pensar en el evento en que se les puede justificar de manera equilibrada, cuando durante la ejecución de un contrato de transporte marítimo, 15 días antes de que se cumpla con la entrega, el lugar en que esta se haría se cambia por otra ciudad. Piensen que si las partes habían pactado la entrega en el puerto de Barranquilla, debido a condiciones 
naturales de ese puerto, es necesario dragarlo y a la llegada del barco a destino, no sería posible desembarcar por riesgo de encallamiento. Ello de manera que se hace necesario desviar al puerto de Santa Marta o al de Cartagena porque el barco no cabe en todo puerto a causa de su calado, así entonces, si el barco hace entrega en Santa Marta, no incumpliría siempre que se haya pactado la modificación unilateral el lugar de manera previa, o para eventos ajenos a las partes lo cual sería válido, de buena fe y equilibrada; debiendo asumir cada parte el sobrecosto, una por el desvío y otra en la recogida de la mercancía.

Entonces parecería que en los contratos de tracto sucesivo es posible hacer ajustes, como en el caso del transporte al cambiar los destinos, si la contraparte lo autorizara por no haberse pactado la cláusula inicialmente, o con más tranquilidad si esa posibilidad quedó pactada en el contrato, e incluso cuando se justifica hacer el ajuste así no se haya pactado, por situaciones de emergencia, necesidad o por una orden del gobierno. Lo que se debe analizar es la buena fe y el equilibrio normativo, según las circunstancias no solo pactadas sino al momento de ejecución y terminación del contrato.

Imaginemos una obligación de custodia como sería aquella que surge en cualquier contrato de depósito, pero debido a una emergencia, como una inundación, o la presencia de alguna situación que haga gravosa la custodia (por ejemplo, una revuelta o un paro como los de reciente ocurrencia, con vandalismo y ataques a inmuebles durante las fiestas de Halloween), complicaría al acreedor para recibir las mercancías en el sitio y hora pactada o que el deudor se las pueda entregar pues se podrían dañar, lo que haría necesario un ajuste unilateral del contrato. Piense en que el deudor decide entregar en otro sitio y avisa un día antes al deudor, lo cual parece equilibrado y razonable (o al menos adecuado a la buena fe), toda vez que el dueño del local decide cerrar y no abrir su local por un tiempo, para evitar que le dañen o saquen las mercancías. Con ese fin, incrementa las medidas de seguridad y como en el caso decide trasladarlas, pero ello, generaría un aumento del precio en el valor de la custodia. No creería que se pueda alegar fuerza mayor pues es resistible, es más fácil hacer la modificación para mantener el contrato y poderlo cumplir con la entrega pactada, pero en otro sitio. En todo caso, es un poder unilateral que algunos consideran que puede llegar a ser abusivo.

Las posiciones en doctrina están divididas, algunos dicen que la variación contractual está prohibida por ser abusiva, a menos que se haga y el otro lo acepte (lo cual es el régimen normal de las obligaciones, donde el acreedor no está obligado más que a la prestación y todas las condiciones pactadas desde un inicio); a menos 
que luego se pacte otra cosa como la entrega en lugar, cantidad, calidad o especificaciones diferentes. Para otros, en cambio, se podría permitir una modificación unilateral bajo una cláusula de previsibilidad contractual, para que ese poder quede en manos de una de las partes frente a ciertas circunstancias ajenas a las partes, operando de manera automática o previo aviso y aceptación.

Tal vez en Derecho de Consumo podría llegar a ser abusiva, pero en Derecho Empresarial no parece que ello sea tan claro. Insisto, creería que lo importante es determinar hasta dónde la cláusula de modificación unilateral es o no equilibrada, hasta dónde es acorde a la buena fe contractual, hasta dónde es acorde a la equidad contractual, a la justicia contractual; porque si viola estos parámetros obviamente sería una cláusula abusiva, pero si no los viola, no se ve por qué no valer tal disposición.

Ahora bien, ¿cuáles podrían ser este tipo de cláusulas de modificación unilateral? Para resolver este interrogante se puede afirmar que unas son las cláusulas de modificación unilateral automática; es decir, aquellas en que se pacta que si se llegan a presentar ciertos eventos, el contrato va a cambiar por una de las partes de manera automática. Pensemos en el cambio de precio. En efecto, el profesor chileno Rodrigo Momberg, considera que estas cláusulas de modificación automática son las que consisten en que ante la ocurrencia de determinados hechos, el contrato se modifica de inmediato; es decir, usted no hace nada pero se ajusta.

Entonces, estas cláusulas de modificación unilateral automática son de dos tipos, las de readaptación y las de actualización. En las de readaptación lo que se pretende es dejar a las partes en condiciones similares a las de contratos presentes o futuros, que celebren las partes incluso con terceros en caso de presentarse ciertas situaciones previstas por las partes. Mientras que en las de actualización, se mantiene el valor de las prestaciones en el tiempo y puede consistir en una simple cláusula de indemnización o de corrección monetaria. Las que en caso de contratos de consumo financiero serían válidas a condición de que el banco le informe al consumidor los ajustes, es decir, deben ser informadas. Pero también se suelen usar en contratos de obra civil, servicios de telecomunicaciones, internet o televisión por cable. Es clásico su uso en los contratos de préstamos bancarios, piense en una cláusula que le permita al banco modificar la tasa de interés, usted pactó su tasa al 10\% y 
debido a esta cláusula y a la inflación, el interés sube. Pero no pensemos en la cláusula de interés fijo, pues su validez sería más compleja, pensemos en la cláusula de interés variable UVR. Así, como pactó UVR, es normal que ella varíe según la inflación, pero qué tal una UVR excesiva: "Pague porque usted pactó eso, hasta que se le informe". Así lo permite el sistema financiero; sin embargo, sería razonable si el banco le cambia su sistema de crédito de manera unilateral a pesos con cuota fija para protegerle.

Lo curioso es que en Colombia con la simple información la cláusula sería válida. En Chile el mismo caso ocurrió con Cencosud, ellos deciden de manera unilateral cambiar la tasa de interés, no obstante, se dio aviso a los usuarios, tal cláusula fue declarada abusiva por la justicia chilena. En Colombia, en cambio, bastaría con simplemente informar para que sea válida, porque así lo permite la ley local. A mi parecer es mucho más acertado el sistema chileno y proteccionista del equilibrio y la buena fe contractual, pues el simple aviso no protege al consumidor y más cuando no tiene opción de poder continuar con el contrato inicial. Lo anterior, dado que al dejarle solo la opción de resolución, en la práctica, no puede resolver ya que no podría ponerse al día con la totalidad del crédito adeudado en una sola cuota, piense en un mutuo a 20 años con garantía hipotecaria. Entonces, el deudor seguirá con el contrato en las condiciones que plantee el banco, a no ser que le decreten la cláusula abusiva y ahí el efecto sería seguir pagando el crédito a la tasa inicialmente pactada.

Ahora, en el caso colombiano, algo similar pasó con la famosa ley que eliminó el UPAC y transformó los créditos así pactados al sistema de crédito en UVR. Allí hubo una cláusula de modificación unilateral en cumplimiento de una ley, porque lo hizo fue el banco. Entonces, la pregunta sigue siendo se puede o no se puede, cuando la ley lo dice está claro, pero por autonomía privada ¿por qué no?, si usted lo pacta de manera previa ¿por qué no? Creería que se podría, siempre que sea equilibrada y acorde a la buena fe.

Ahora, otro tipo de cláusulas son las que le permiten a una de las partes modificar unilateralmente el contrato, pero ahora la adaptación no se podrá hacer de manera automática; sino que el ajuste sobre el servicio, se hará por la parte de manera unilateral, si luego que se informe sobre el cambio hay autorización para que pueda válidamente prosperar el ajuste.

Así, sería válido para el banco ajustar las tasas, plazos o fechas, incluso cambiar las condiciones contractuales, pero porque lo autorizaron. Inclusive, se le podría dar el poder de modificación unilateral no solo a la parte (el banco), sino a un tercero que determine 
cuál sería el ajuste. El problema es ver hasta dónde ese ajuste hecho por el tercero es equilibrado o no.

También se encuentran, en ámbito internacional, las cláusulas que hacen que ante ciertas circunstancias el contrato requerirá de la renegociación del mismo, es decir, las famosas cláusulas hardship, o de excesiva onerosidad. Son estas cláusulas, en las que en caso de que se den ciertos eventos determinados graves, las partes se obligan a que se haga un arreglo de renegociación del contrato y la revisión de los acuerdos.

Para finalizar, un ejemplo que no solo se refiere la cambio o ajuste de precio. Pensemos en el cambio del lugar de destino sin previo aviso, por ejemplo, si de un momento a otro el gobierno prohíbe la importación de ciertos productos que ya habían sido enviados a Buenaventura; entonces como acreedor comprador doy aviso sobre la situación legal de mi país y le cambio al transportador el lugar de entrega y coloco como nuevo destino Colón, esto sería razonable para evitar la resolución y devolución de mercancías, además de la asunción del sobrecosto, si lo hay.

Gracias a este tipo de cláusulas, es posible que se hagan cambios de calidad, volumen, número de cantidades de productos, precio, tasas de interés, diseños, etc. En todo caso, ellas no deben ser sorpresivas pues deben estar pactadas y los cambios equilibrados, y acorde a la buena fe; pues no parecería muy acorde a la buena fe, que se muestre una publicidad y luego se cambie lo de la publicidad vendida por otra cosa. Piense en que compro un apartamento porque en las zonas comunes aparecía un jardín y una piscina y luego le dicen que eso ya no se hará, pero el precio se mantiene y sin derecho a resolución del contrato de promesa, que versa sobre una venta que aún no se ha celebrado. Y si lo resuelve se le cobra, además, la cláusula penal que no aparecía en la promesa, sino en el contrato de venta.

En todo caso, lo que se aconseja es que se pacten, y solo para eventos que no dependen de la voluntad de las partes. Si se han pactado para que se modifique el contrato, por un evento que depende solo de una las partes, parecería ser una cláusula que da lugar a una obligación puramente potestativa, lo cual sería contra el Derecho Obligacional. 
También parece adecuado que, al ajustarse el precio, se tenga también una contraprestación, un equilibrio en la contraparte, como sería el derecho a resolver o terminar o incluso a que un tercero o el juez ajuste las prestaciones o el precio mismo. Sin embargo, dejar esa potestad al juez parecería contradecir la autonomía privada, pero es muy cercano a la teoría de la imprevisión pactada por unas cláusulas de previsión que permitiría, sin dudas, que se hagan unos ajustes que permitan seguir con la continuidad del contrato, no obstante, situaciones sobrevenidas que dificultan su ejecución. 